\title{
Diurnal Temperature Range in Winter Wheat Growing Regions of China: CMIP6 Model Evaluation and Comparison
}

\section{Wenqiang Xie}

Beijing Normal University

\section{Shuangshuang Wang}

Beijing Normal University

Xiaodong Yan ( $\nabla$ yxd@bnu.edu.cn )

Beijing Normal University https://orcid.org/0000-0002-0774-9140

\section{Research Article}

Keywords: CMIP6, Winter wheat, Diurnal temperature range, Yield, China

Posted Date: November 17th, 2021

DOI: https://doi.org/10.21203/rs.3.rs-1005239/v1

License: (c) (i) This work is licensed under a Creative Commons Attribution 4.0 International License.

Read Full License 


\section{Abstract}

Diurnal temperature range (DTR) is an important meteorological component affecting the yield and protein content of winter wheat. The accuracy of climate model simulations of DTR will directly affect the prediction of winter wheat yield and quality. Previous model evaluations for worldwide or nationwide cannot answer which model is suitable for the estimation of winter wheat yield. We evaluated the ability of the coupled model intercomparison project phase 6 (CMIP6) models to simulate DTR in the winter wheat growing regions of China using $\mathrm{CNO5}$ observations. The root mean square error (RMSE) and the interannual varibility skill score (IVS) were used to quantitatively evaluate the ability of models in simulating DTR spatial and temporal characteristics, and the comprehensive rating index (CRI) was used to determine the most suitable climate model for winter wheat. The results showed that the CMIP6 model can reproduce DTR in winter wheat growing regions. BCC-CSM2-MR simulations of DTR in the winter wheat growing season were more consistent with observations. EC-Earth3-Veg simulated the climatological DTR best in the wheat growing regions (RMSE=0.848). Meanwhile, the evaluation for climatological DTR in China is not applicable to the evaluation of DTR in winter wheat growing regions, and the evaluation for annual DTR is not a substitute for the evaluation for winter wheat growing season DTR. Our study highlights the importance of evaluating winter wheat growing regions' DTR, which can further improve the ability of CMIP6 models simulating DTR to serve the research of climate change impact on winter wheat yield.

\section{Introduction}

Winter wheat is widely grown in China ( Cao et al., 2011; Song and Dong, 2006) and is one of the major food sources for humans. The changes in winter wheat yield and quality are related to the food security of human society. The yield and protein content of wheat is known to be influenced by the environment and other factors (Rao et al., 1993; Baenziger et al., 1985; Vaughan et al., 1990; Smika and Greb, 1973; Tao et al.,2010). Temperature is a major factor affecting crop growth and production (Lobell et al., 2008; Schlenker et al., 2009). The optimum temperature required for different fertility stages of the crop is not consistent, so the air temperature can affect the crop positively or negatively (Baker et al.,1993). In the past 20-30 years, the effects of temperature rise on crop yield and phenology have been observed in the United States and Germany (Chmielewski et al., 2004; Lobell and Asner, 2003). It was also observed in China that the warming trend shifted crop phenology and impacted crop yields (Tao et al., 2006; Lobell et al., 2011). In addition, precipitation and other meteorological components can also affect the growth and yield of winter wheat. Water is essential for the survival and growth of winter wheat, if the water supply is insufficient, it will affect the physiological functions of winter wheat, which will lead to changes in its phenology and yield (Viala et al., 2008). The impact of precipitation on modern agriculture has been greatly reduced with the progress of farming technology and social development. Therefore, at the current level of technology, air temperature is one of the main meteorological components that affect the growth and development of winter wheat. 
The quality and yield of winter wheat are influenced by the diurnal temperature range (DTR). DTR is one of the most important agro-meteorological variables in agricultural production. DTR is an important factor affecting the yield and protein content of winter wheat (Wang et al., 1990). To quantitatively assess the impact of climate change on wheat yield and quality, scholars have conducted a considerable number of experiments (Aronson et al., 2009; Ortiz et al.,2008). However, previous studies have focused on the effects of air temperature and extreme weather events on winter wheat yield, and only a few studies paid attention to DTR (Tian et al.,2014). It is reported that changes in daily maximum temperature and minimum temperature may have different influences on crops (Dhakhwa et al.,1998; Tubiello et al., 2002), lower daily minimum temperature helps to improve crop quality. DTR is an important factor affecting the yield and protein content of winter wheat (Wang et al., 1990). Jiang (2013) indicated that a decrease in DTR in spring and summer was beneficial for crop yield increase, while an increase in DTR in fall was beneficial. There are still some major uncertainties in wheat production under future climates due to the uncertainty of future changes in DTR.

There are still large uncertainties in the simulation of DTR by climate models. The assessment results for air temperature cannot replace the assessment for DTR. The Coupled Model Intercomparison Project Phase 6 (CMIP6) is the latest experiment in simulating global climate through climate models. It brings together the world's best models and conducts the most colorful experiments with comprehensive coverage of the world and long-time series. The latest studies have analyzed and evaluated model simulations for a wide range of climate variables. According to previous studies, climate models have reasonable confidence in the simulation of global surface air temperature (SAT), climate extremes, atmospheric circulation, and other elements (Zhou et al., 2006; Lorenz R et al., 2014; Sillmann J et al. 2013a, 2013b; Zhou et al. 2014; Chen and Sun, 2015; Gao et al., 2021). The IPCC Fifth Assessment Report (2013) indicated that the CMIP5 model can well reproduce the large-scale surface temperature patterns, but that in many regions there are large uncertainties in the trends and possible interpretations of DTR (Christy J R, et al., 2006; Fall et al., 2011; Zhou and Ren, 2011). Lewis and Karoly (2013) evaluated the DTR simulated by 27 CMIP5 climate models in four land surface regions (North America, Europe, midlatitude Asia, and Australia) and pointed out that the DTR has decreased in the past 50 years, and the changes simulated by these models are smaller than those observed. Lindvall and Svensson (2015) evaluated the simulation ability of 20 CMIP5 models in simulating the terrestrial DTR of recent and future projections using HadGHCND and CRU and found that the DTR varies considerably between CMIP5 models and that the DTR is often underestimated. This uncertainty creates a great deal of confusion in applying the results of climate models to assess the extent to which crops are exposed to climate change. In summary, although the CMIP6 model already has a good simulation capability for air temperature and precipitation, the simulation capability for important agrometeorological elements such as DTR still needs to be improved.

Considerable studies have been conducted by scholars to quantitatively assess the simulation of key meteorological elements by climate models (Slafer et al., 1995; Larmure et al., 2005). However, few have evaluated climate models simulations for DTR. The spatial scales of previous assessments have focused on worldwide or nationwide (Wang et al., 2020), and only a few studies have been conducted on the scale 
of crop-growing regions. Meanwhile, previous assessments mainly evaluated the ability to simulate the interannual variability of meteorological components on the time scale (Lewis et al., 2013), and only a few studies were conducted within the growth period of crops. As a largely agricultural country, China should be more concerned about the impact of climate change on crops. Therefore, the more important question for our scholars is: How well do climate models simulate meteorological elements in crop production areas in China? Which models are applicable to the study of crops? Until now, few have quantitatively evaluated the ability of the CMIP6 climate model to simulate DTR in winter wheat growing areas in China. Therefore, we quantitatively evaluated the ability of the CMIP6 model to simulate the spatial and temporal characteristics of DTR in winter wheat growing regions in China from multiple perspectives and selected the most suitable model to simulate winter wheat DTR. It helps to further improve the ability of global climate models to simulate DTR in winter wheat growing areas in China, to serve the research of climate change impact on winter wheat yield and quality.

\section{Data And Methods}

\subsection{CMIP6 Model outputs}

CMIP6 takes into account the effects of external forcing, including natural factors and human activities, over time in the simulation of historical periods. Global near-surface maximum air temperature and minimum air temperature data simulated by twenty-six CMIP6 models from 1961 to 2014 were retrieved from the CMIP6 website (https://esgf-node.IInl.gov/search/cmip6). The model data used in this study were the simulated results of the near-surface maximum air temperature (Tasmax) and near-surface minimum air temperature (Tasmin) simulated by 26 CMIP6 models to calculate the DTR. Table 1 shows the information of each model. 


\begin{tabular}{|c|c|c|c|}
\hline No. & Model name & Institution (Country) & Resolution \\
\hline 1 & ACCESS-CM2 & CSIRO-ARCCSS (Australia) & $1.875^{\circ} \times 1.25^{\circ}$ \\
\hline 2 & ACCESS-ESM1-5 & CSIRO (Australia) & $1.875^{\circ} \times 1.24^{\circ}$ \\
\hline 3 & AWI-CM-1-1-MR & AWI (Germany) & $0.9375^{\circ} \times 0.9375^{\circ}$ \\
\hline 4 & AWI-ESM-1-1-LR & AWI (Germany) & $1.875^{\circ} \times 1.875^{\circ}$ \\
\hline 5 & BCC-CSM2-MR & BCC (China) & $1.125^{\circ} \times 1.125^{\circ}$ \\
\hline 6 & BCC-ESM1 & BCC (China) & $2.8125 \times 2.8125$ \\
\hline 7 & CanESM5 & CCCma (Canada) & $2.8125^{\circ} \times 2.8125^{\circ}$ \\
\hline 8 & EC-Earth3 & EC (Sweden) & $0.703^{\circ} \times 0.703^{\circ}$ \\
\hline 9 & EC-Earth3-Veg & EC (Sweden) & $0.703^{\circ} \times 0.703^{\circ}$ \\
\hline 10 & EC-Earth3-Veg-LR & EC (Sweden) & $1.125^{\circ} \times 1.125^{\circ}$ \\
\hline 11 & FGOALS-f3-L & CAS (China) & $1.25^{\circ} \times 1.25^{\circ}$ \\
\hline 12 & FGOALS-g3 & CAS (China) & $2.0^{\circ} \times 2.0^{\circ}$ \\
\hline 13 & GFDL-CM4 & NOAA-GFDL (America) & $1.25^{\circ} \times 1.25^{\circ}$ \\
\hline 14 & GFDL-ESM4 & NOAA-GFDL (America) & $1.25^{\circ} \times 1.0^{\circ}$ \\
\hline 15 & GISS-E2-1-G & NASA-GISS (America) & $2.5^{\circ} \times 2.0^{\circ}$ \\
\hline 16 & INM-CM4-8 & INM (Russia) & $2.0^{\circ} \times 1.5^{\circ}$ \\
\hline 17 & INM-CM5-0 & INM (Russia) & $2.0^{\circ} \times 1.6^{\circ}$ \\
\hline 18 & IPSL-CM6A-LR & IPSL (France) & $2.5^{\circ} \times 1.25^{\circ}$ \\
\hline 19 & KIOST-ESM & KIOST (Korea) & $1.875^{\circ} \times 1.875^{\circ}$ \\
\hline 20 & MIROC6 & MIROC (Japan) & $1.40625^{\circ} \times 1.40625^{\circ}$ \\
\hline 21 & MPI-ESM-1-2-HAM & MIROC (Germany) & $1.975^{\circ} \times 1.975^{\circ}$ \\
\hline 22 & MPI-ESM1-2-HR & MPI-M (Germany) & $0.9375^{\circ} \times 0.9376^{\circ}$ \\
\hline 23 & MPI-ESM1-2-LR & MPI-M (Germany) & $1.875^{\circ} \times 1.875^{\circ}$ \\
\hline 24 & MRI-ESM2-0 & MRI (Japan) & $1.125^{\circ} \times 1.126^{\circ}$ \\
\hline 25 & NorESM2-MM & NCC (Norway) & $1.25^{\circ} \times 0.9375^{\circ}$ \\
\hline 26 & NESM3 & NUIST (China) & $1.875^{\circ} \times 1.875^{\circ}$ \\
\hline
\end{tabular}

Table 1. Information of CMIP6 models. 
To evaluate the simulated results of the CMIP6 models, the daily maximum and minimum temperature data of the China high-resolution dataset CN05.1 released by the Open Laboratory for Climate Research of China Meteorological Administration (Wu et al., 2013) were used as observational data in this study. The available starting and ending times of these data are 1961-2018, with a high spatial resolution of $0.5^{\circ} \times 0.5^{\circ}$. This dataset has a long period and high spatial resolution. The generation process of this dataset only used the actual observational data of observation stations for statistical interpolation, covering the entire land area of China (Taiwan province is missing statistical data). Compared with the reanalysis data, the CN05.1 data have greater reliability.

The data of all models were interpolated uniformly to a $0.5^{\circ} \times 0.5^{\circ}$ grid using the bilinear interpolation method. Due to the different periods of the model data and observational data, only China's land area was considered in this study, and the study period from 1961 to 2014 was 54 years in total.

\subsection{Methods}

To facilitate the analysis, a bilinear interpolation method was adopted to interpolate the model data uniformly to the same resolution, corresponding to the grid positions and resolutions of the observed datasets.

According to the Atlas of Fine Agricultural Climatic Resources in China (Mao et al., 2018) and Harvested Area and Yield for 175 Crops (Monferda et al.,2008), the main growing regions of winter wheat in China were selected as the study regions and extracted from the above grid points. All assessments were conducted on these grid points.

According to the research of $\mathrm{Wu}(2020)$ and combined with the distribution of winter wheat-growing regions, China was divided into eight subregions in this study. The regional divisions in China are shown in Figure 1.

\subsubsection{Evaluation of climatological DTR}

The historical simulation experiments in CMIP6 were conducted from 1850 to 2014, while different future scenarios were divided from 2015 onwards. The period from 1995-2014 can better represent the current climate state and help us understand the simulation capability of the CMIP6 model for the current climate state. Therefore, the climatology from 1995-2014 was selected to evaluate the simulation ability of CMIP6 models to the spatial distribution of the DTR in winter wheat-growing regions in China.

\subsubsection{Evaluation of DTR in the winter wheat-growing season}

The research results of Wang (2020) indicated that the reviving and maturity periods of winter wheat in northern China mainly occur from March to June. In this study, March to June of the current year was selected as the winter wheat-growing season. 54 years of data from 1961 to 2014 were selected for analysis in this study. The annual mean DTR and the winter wheat growing season mean DTR simulated 
by CMIP6 models in winter wheat growing regions were calculated and compared. The Interannual varibility skill scores (IVS) were calculated for each model.

\subsubsection{Multimodel ensemble method}

It was revealed in previous studies that the multimodel ensemble mean usually shows higher reliability to reproduce the present Chinese climate relative to an individual model (Jiang et al., 2005, 2009). Therefore, the multimodel arithmetic mean ensemble with the same weights (MME) was used in this study as the multipattern ensemble method.

\subsubsection{Performance Metrics}

In the evaluation of the CMIP6 model's simulation capability to DTR in winter wheat-growing regions in China, the following indexes were used.

To further evaluate the overall skills of the CMIP6 model for DTR simulation in China's winter wheatgrowing regions, root mean square error (RMSE) was used. RMSE is:

$$
R M S E=\sqrt{\frac{1}{N} \sum_{i=1}^{N}\left(M_{t}-a_{l}\right)^{2}}
$$

Where Mi and $\mathrm{Oi}$ are the simulated value and the observation of the ith grid, respectively. $\mathrm{N}$ is the grid number. The RMSE is bigger than 0 . When RMSE is 0 , it indicates that the pattern matches the observation perfectly; the smaller RMSE indicates the pattern has better performance.

The Interannual varibility skill score (IVS) is used to quantitatively express the ability of models in simulating the interannual variability. IVS is:

$$
I V S=\left(\frac{\sigma_{m}}{\sigma_{o}}-\frac{\sigma_{o}}{\sigma_{m}}\right)^{2}
$$

where $\sigma_{\mathrm{m}}$ and $\sigma_{\mathrm{o}}$ denotes the interannual standard deviation of simulated variables and observed variables. The IVS value is equal to 0 when $\sigma_{\mathrm{m}}$ is indentical to $\sigma_{\mathrm{m}}$ and the closer the IVS value is to 0 , the greater skill in simulating the interannual variability.

To evaluate the ability of models to simulate both climatic state DTR and interannual variability, this study comprehensively ranks the simulation ability of each CMIP6 model based on RMSE and IVS. The Comprehensive Rating Index (CRI) enables efficient ranking of model simulation values (Jiang et al., 2015). CRI is:

$$
C R I=1-\frac{1}{n \times m} \sum_{i=1}^{n} \operatorname{rank}_{i}
$$


where $\mathrm{n}$ is the number of evaluation indicators, $\mathrm{m}$ is the number of models, and rank $\mathrm{k}_{\mathrm{i}}$ is the ranking of the ith indicator of the model. The closer the CRI value is to 1 , the better the model simulation is.

\section{Results}

\subsection{Evaluation of climatological DTR}

The CMIP6 models can reproduce the spatial characteristics of climatological DTR in winter wheat growing regions(Figure 2): The DTR increased gradually from low to high latitudes and ranged from $8^{\circ} \mathrm{C}$ to $12^{\circ} \mathrm{C}$ in winter wheat growing regions. The DTR gradually increased from coastal to inland regions, with higher DTR in NEC and TP than in other regions.

When comparing with observations, the multimodel ensemble data are approximately $3^{\circ} \mathrm{C}$ lower than the observations nationwide and $6^{\circ} \mathrm{C}$ lower in NEC. In addition, the DTR in $\mathrm{CY}$ is $2^{\circ} \mathrm{C}$ higher than the observation.

EC-Earth3-Veg has the best simulation ability among 26 CMIP6 models for simulating the climatological DTR both in China (RMSE=1.388) and winter wheat-growing regions (RMSE=1.018). DTR simulated by MME was not as good as EC-Earth3-Veg both in China and in the wheat growing regions. The same conclusions can be drawn across the country. The simulation of EC-Earth3-veg is relatively small in SWC compared to the observation, while in other regions they are approximately $1^{\circ} \mathrm{C}$ higher. It shared the same characteristics in China, but in NEC, the simulation was about $3^{\circ} \mathrm{C}$ lower, and the deviations were more than $5^{\circ} \mathrm{C}$ in some areas.

There was geographical variability in the distribution of standard deviations among models. (Figure 3 ). The mean SD within winter wheat growing regions is 2.33 , and in China, the SD is 2.72 . The consistency within winter wheat growing regions is higher than that in China. The SD of simulations in NEC and TP are about $4^{\circ} \mathrm{C}$ higher than the other regions, and there are significant differences between models. The SD of the simulated results in Xinjiang is slightly higher, and CMIP6 models have significant differences in this region. It indicates that CMIP6 models have good simulation capability in eastern China. In NEC and TP, there are great differences between the simulated results of different models. It indicated that CMIP6 models are still deficient in their ability to simulate the climatological DTR in TP, which is consistent with CMIP5. Improving the model to make the simulation more reliable has become a new challenge for model developers.

We evaluated each region and calculated the RMSE for each model separately, the evaluation results are presented in Figure 4 to show the comprehensive performance of the model more visually.

In general, the CMIP6 model can reproduce the spatial distribution of climatological DTR (Fig. 4), and most of the models had RMSEs less than 2. CMIP6 model performed better in simulating DTR in winter wheat growing regions than that in China $\left(\mathrm{RMSE}_{\mathrm{G}}\right.$ was smaller than $\left.\mathrm{RMSE}_{\mathrm{N}}\right)$. EC-Earth3-Veg had better simulation effects for both nationwide (RMSE=1.388) and growing regions (RMSE=1.018) relative to the 
other models, and the MME showed the same characteristics. However, the difference between MME (RMSE $=1.28$ ) and observation was slightly greater than that of EC-Earth3-Veg. There were large differences in model performance across regions: for different regions, EC-Earth3-Veg had the smallest RMSE and the highest ranking in NC, SWC, and CY, which is consistent with the results of the nationwide and winter wheat growing regions evaluations. However, the simulation ability of EC-Earth3-Veg was not the best in $\mathrm{JH}$ and SWC. This suggests that even the model with the best performance among the 26 models may not have the best performance in all regions. The results show that the CMIP6 model has better simulations in JH (mean RMSE $=0.780)$ and NC (RMSE = 1.022); the simulations in NWC (RMSE = 1.78) are more different from observations.

\subsection{Evaluation of DTR in the winter wheat-growing season}

According to the observations, the growing season DTR in wheat growing regions shows a decreasing trend at a rate of $-0.080^{\circ} \mathrm{C} / 10 \mathrm{a}$ (Figure 5). The same trend is observed for the annual DTR, with the decreasing rate of $-0.108^{\circ} \mathrm{C} / 10 \mathrm{a}$. The annual DTR showed a greater rate of decline relative to the winter wheat growing regions. CMIP6 models can better simulate these trends (Figure 6): among 26 CMIP6 models, GISS-E2-1-G had the best simulations for the annual DTR trend $\left(-0.110^{\circ} \mathrm{C} / 10 \mathrm{a}\right)$; BCC-CSM2-MR performed best in winter wheat growing regions $\left(-0.083^{\circ} \mathrm{C} / 10 \mathrm{a}\right)$. The MME can simulate these trends with slower rates.

In general, CMIP6 models were able to simulate the interannual variation of annual DTR and growing season mean DTR in winter wheat growing regions. Most of the CMIP6 models had IVSs less than 0.9. The CMIP6 model simulated the winter wheat growing season DTR significantly different from the simulation of the annual DTR, and some models simulated the annual DTR better than the simulation of the growing season DTR. Similarly, it has been reported that CMIP5 simulated interannual variability of annual air temperature better than monthly and seasonal temperature. It is worth noting that models with good simulations of annual DTR were slightly inferior in simulating growing-season mean DTR, while models with good simulations of growing-season mean DTR showed unsatisfactory simulations for interannual variation of annual DTR (Figure 7). The model with a good simulation of annual DTR does not imply a good simulation of the winter wheat growing season; therefore, targeted evaluation for the winter wheat growing season becomes essential. BCC-CSM2-MR had the best ability to simulate DTR for the winter wheat growing season, and it was more suitable for studies targeting the winter wheat growing season compared with the interannual variation. The performance of the CMIP6 model varies greatly across regions (Figure 7). The MME was more suitable for the simulation of annual DTR.

\subsection{Overall model ordering}

To comprehensively evaluate the ability of each model simulating the spatial and temporal characteristics of DTR in winter wheat growing regions, the CRI was used to evaluate each model in this study. According to Table 2, EC-Earth3-Veg-LR had the best simulation of DTR in winter wheat growing regions $(\mathrm{CRI}=0.85)$, which is more suitable for the simulation of DTR in winter wheat growing regions in China. 
Table 2. CRI of CMIP6 models.

\begin{tabular}{llll} 
Model name & CRI & Model name & CRI \\
\hline ACCESS-CM2 & 0.60 & GFDL-ESM4 & 0.63 \\
\hline ACCESS-ESM1-5 & 0.48 & GISS-E2-1-G & 0.62 \\
\hline AWI-CM-1-1-MR & 0.56 & INM-CM4-8 & 0.71 \\
\hline AWI-ESM-1-1-LR & 0.38 & INM-CM5-0 & 0.62 \\
\hline BCC-CSM2-MR & 0.58 & IPSL-CM6A-LR & 0.25 \\
\hline BCC-ESM1 & 0.46 & KIOST-ESM & 0.19 \\
\hline CanESM5 & 0.33 & MIROC6 & 0.33 \\
\hline EC-Earth3 & 0.79 & MPI-ESM-1-2-HAM & 0.31 \\
\hline EC-Earth3-Veg & 0.81 & MPI-ESM1-2-HR & 0.46 \\
\hline EC-Earth3-Veg-LR & 0.85 & MPI-ESM1-2-LR & 0.63 \\
\hline FGOALS-f3-L & 0.13 & MRI-ESM2-0 & 0.44 \\
\hline FGOALS-g3 & 0.08 & NorESM2-MM & 0.19 \\
\hline GFDL-CM4 & 0.56 & NESM3 & 0.52
\end{tabular}

\section{Discussion}

There are uncertainties in the simulation of DTR by climate models. To explore the applicability of the CMIP6 model to crop research, we evaluated the ability of the CMIP6 model to simulate DTR in winter wheat growing regions in China. The results show that consistent with CMIP5 (Lindvall and Svensson, 2015), CMIP6 can reproduce the spatial distribution of climatological DTR. The CMIP6 model had significant differences in simulating DTR in western China and had the same characteristics as other meteorological components (Guo et al., 2013; Zhou and Yu, 2006; Xu and Xu, 2012), which might be related to the complex topography of NWC (Hu et al., 2014). The CMIP6 model simulated the climatological DTR of winter wheat growing regions better than that of DTR in China, but there were differences in the rankings between models. In winter wheat growing regions, both annual DTR and growing season mean DTR showed slow decreasing trends. The decreasing DTR trend has been universally observed since the 1950s (Karl et al., 1993; Easterling et al., 1997; You et al., 2017; Wang and Clow, 2020). The CMIP6 model simulates the annual DTR better than the growing season DTR, and the same characteristics can be found in the simulations of meteorological components such as temperature and precipitation (Xia et al., 2015; Kamworapan, S., \& Surussavadee, 2019). This difference makes it critical and essential to perform the targeted model evaluation of the winter wheat growing season. Although a considerable number of studies have been conducted to assess the simulation capability of 
climate models for key meteorological components. However, the spatial scales of previous assessments have been mainly for worldwide or nationwide. Only a few studies have been conducted for crop-growing regions. Meanwhile, few studies were conducted within the crop growing season. Our study evaluated the model's ability to simulate climatological DTR for winter wheat growing regions and China, as well as the ability to simulate growing season DTR versus annual DTR, and found large differences in model performance. When estimating future climate impacts on winter wheat, using inappropriate climate model data would greatly reduce the credibility of the study results. Therefore, climate model evaluation for winter wheat can make essential contributions to the accurate estimation of future changes in winter wheat yield and quality.

This study only evaluates the DTR of the winter wheat growing area in China, and the ability of the climate model to simulate other climate components in the winter wheat growing area in China needs to be further evaluated. Meanwhile, the scope of our study is limited in China, and the simulation capability of the climate model in other regions and globally needs to be further evaluated.

\section{Conclusions}

The ability of the CMIP6 model to simulate the spatial and temporal characteristics of DTR in winter wheat growing regions can be understood by evaluating the simulations of the CMIP6 model. Our study provides a better definition of the scope for model evaluations of winter wheat by using actual winter wheat growing regions. Therefore, more targeted results can be obtained when quantitatively evaluating the ability of climate models to simulate key agrometeorological components. In this study, the performance of CMIP6 models in reproducing the DTR in winter wheat-growing regions in China was analyzed by comparing model simulations with observations. The CMIP6 model can reproduce the spatial and temporal distribution characteristics of DTR in winter wheat growing regions in China, but there are discrepancies in performance between models. The main conclusions are summarized as follows:

(1) CMIP6 models can generally reproduce the spatial distribution and interannual variation of DTR in winter wheat growing regions. The CMIP6 model can simulate the DTR of winter wheat growing regions better than that in China $\left(\mathrm{RMSE}_{\mathrm{G}}\right.$ was smaller than $\left.\mathrm{RMSE}_{\mathrm{N}}\right)$.

(2) The evaluation for China cannot replace the evaluation for winter wheat growing regions, and it does not imply that the results of model evaluation within China are fully applicable to winter wheat growing regions. Compared with other models, EC-Earth3-Veg had the best simulation ability for climatic state DTR in winter wheat growing regions; meanwhile, EC-Earth3-Veg performed better in the winter wheat growing regions than that in China.

(3) The evaluation of annual DTR cannot replace the evaluation of winter wheat growing season DTR, and the model with a good simulation of annual DTR does not indicate that the results are suitable for the simulation of winter wheat growing season DTR. BCC-CSM2-MR has the best performance in 
simulating the DTR of the winter wheat growing season and it is more suitable for winter wheat seasonal studies.

(4) The evaluation of the CMIP6 model's comprehensive ability to simulate DTR in winter wheat growing regions showed that EC-Earth3-Veg-LR is more suitable for simulating DTR in winter wheat growing regions $(\mathrm{CRI}=0.85)$ than other models.

In summary, when studying the relationship between climate and crops, attention should be paid to the selection of models most suitable for the study of the crop growing season and growing regions of the crops under study, rather than simply selecting climate models with good simulation effects throughout the country or the year.

\section{Declarations}

\section{Acknowledgments}

We would like to thank the China Meteorological Administration for temperature data and information. We also acknowledge the Coupled Model Intercomparison Project (CMIP) launched by the World Climate Research Program (WCRP) for CMIP6 data.

\section{Funding Statement}

This work was supported by the National Key Research and Development Program of China [grant number 2019YFA0606904].

\section{Author's Contribution}

All authors have read and agreed to the published version of the manuscript. Wenqiang Xie analyzed data and wrote the original draft. Shuangshuang Wang organized the original data. Xiaodong Yan conceived and designed the study.

\section{Availability of data and material}

All data sets used in this study are publicly available.

\section{Code availability}

Python code developed for this study is available from the authors upon request.

\section{Ethics approval}

The manuscript is conducted within the ethical manner advised by the Theoretical and Applied Climatology. Permissions or licenses were obtained.

\section{Consent to participate}


Not applicable.

\section{Consent for publication}

Authors agree to publish this paper.

\section{Conflicts of interest}

The authors declare no conflict of interest.

\section{Author information}

\section{Affiliations}

State Key Laboratory of Earth Surface Processes and Resource Ecology, Faculty of Geographical Science, Beijing Normal University, Beijing 100875, China

Wenqiang Xie, Shuangshuang Wang, Xiaodong Yan

\section{Corresponding author}

Correspondence to Xiaodong Yan. E-mail: yxd@bnu.edu.cn. Tel:(+86)13511027765

\section{References}

Aronson, E. L., \& McNulty, S. G. (2009). Appropriate experimental ecosystem warming methods by ecosystem, objective, and practicality. Agricultural and Forest Meteorology, 149(11), 1791-1799. https://doi.org/10.1016/j.agrformet.2009.06.007.

Baenziger, P. S., Clements, R. L., McIntosh, M. S., Yamazaki, W. T., Starling, T. M., Sammons, D. J., \& Johnson, J. W. 1985. Effect of Cultivar, Environment, and Their Interaction and Stability Analyses on Milling and Baking Quality of Soft Red Winter Wheat 1. Crop Science, 25(1), 58. https://doi.org/10.2135/cropsci1985.0011183X002500010002x.

Baker, J. T., \& Allen, L. H. (1993). Contrasting crop species responses to CO 2 and temperature: rice, soybean, and citrus. Vegetatio, 104(1), 239-260. https://doi.org/10.1007/BF00048156.

Cao, Q., Yao, F., Lin, E., Zhang, J., Wang, P., \& Qin, P. 2011. Analysis of changing characteristics of agricultural climate resources in the main planted areas of winter wheat in China over last 50 years. Chinese Journal of Agrometeorology, 32(02), 161. https://doi.org/10.3969/j.issn.1000-6362.2011.02.002.

Chen, H., \& Sun, J. 2015. Changes in climate extreme events in China associated with warming. International Journal of Climatology, 35(10), 2735-2751. https://doi.org/10.1002/joc.4168. 
Chmielewski, F. M., Müller, A., \& Bruns, E. (2004). Climate changes and trends in phenology of fruit trees and field crops in Germany, 1961-2000. Agricultural and Forest Meteorology, 121(1-2), 6978. https://doi.org/10.1016/S0168-1923(03)00161-8.

Christy, J. R., \& Norris, W. B. 2006. Satellite and VIZ-radiosonde intercomparisons for diagnosis of nonclimatic influences. Journal of Atmospheric and Oceanic Technology, 23(9), 11811194. https://doi.org/10.1175/JTECH1937.1.

Dhakhwa, G. B., \& Campbell, C. L. (1998). Potential effects of differential day-night warming in global climate change on crop production. Climatic Change, 40(3), 647-667. https://doi.org/10.1023/A:1005339800665.

Easterling, D. R., Horton, B., Jones, P. D., Peterson, T. C., Karl, T. R., Parker, D. E., ... \& Folland, C. K. 1997. Maximum and minimum temperature trends for the globe. Science, 277(5324), 364-

367. https://doi.org/10.1126/science.277.5324.364.

Fall, S., Watts, A., Nielsen-Gammon, J., Jones, E., Niyogi, D., Christy, J. R., \& Pielke Sr, R. A. 2011. Analysis of the impacts of station exposure on the US Historical Climatology Network temperatures and temperature trends. Journal of Geophysical Research: Atmospheres, 116(D14). https://doi.org/10.1029/2010JD015146.

Gao, Z., J. Zhu, Y. Guo, N. Luo, Y. Fu, and T. Wang .2021, Impact of Land Surface Processes on a RecordBreaking Rainfall Event on May 06-07, 2017, in Guangzhou, China, Journal of Geophysical Research: Atmospheres, 126(5). https://doi.org/10.1029/2020jd032997.

Guo Y., Dong W., Ren F., Zha Z.\& Huang J. 2013. Surface air temperature simulations over China with CMIP5 and CMIP3. Advances in climate change research, 4(3), 145-

152. https://doi.org/10.3724/SP.J.1248.2013.145.

Hu, Q., Jiang, D., \& Fan, G. 2014. Evaluation of CMIP5 models over the Qinghai-Tibetan Plateau. Chin. J. Atmos. Sci, 38, 924-938. https://doi.org/10.3878/j.issn.1006-9895.2013.13197.

IPCC, 2013: Climate Change 2013: The Physical Science Basis. Contribution of Working Group I to the Fifth Assessment Report of the Intergovernmental Panel on Climate Change [Stocker, T.F., D. Qin, G.-K. Plattner, M. Tignor, S.K. Allen, J. Boschung, A. Nauels, Y. Xia, V. Bex and P.M. Midgley(eds.)]. Cambridge University Press, Cambridge, United Kingdom and New York, NY, USA, 1535 pp.

Jiang, D.,Wang, H., Lang X. 2005. Evaluation of East Asian climatology as simulated by seven coupled models. Advances in Atmospheric Sciences, 22(4), 479-495. https://doi.org/10.1007/BF02918482.

Jiang, L. X., Lv, J. J., Wang, L. L., Yang, X. Q., \& Li, S. 2013. Variation of Diurnal Temperature Range and its Relationship with Crop Yield in Heilongjiang Province. Chinese Journal of Agrometeorology, 02. 
Jiang, Z., Li, W., Xu, J., \& Li, L. (2015). Extreme precipitation indices over China in CMIP5 models. Part I: Model evaluation. Journal of Climate, 28(21), 8603-8619. https://doi.org/10.1175/JCLI-D-15-0099.1.

Kamworapan, S., \& Surussavadee, C. 2019. Evaluation of CMIP5 global climate models for simulating climatological temperature and precipitation for Southeast Asia. Advances in Meteorology, 2019. https://doi.org/10.1155/2019/1067365.

Karl, T. R., Jones, P. D., Knight, R. W., Kukla, G., Plummer, N., Razuvayev, V., ... \& Peterson, T. C. 1993. Asymmetric trends of daily maximum and minimum temperature. Papers in Natural Resources, 185.

Larmure, A., Salon, C., \& Munier-Jolain, N. G. (2005). How does temperature affect C and N allocation to the seeds during the seed-filling period in pea? Effect on seed nitrogen concentration. Functional Plant Biology, 32(11), 1009-1017. https://doi.org/10.1071/FP05154.

Lewis, S. C., \& Karoly, D. J. 2013. Evaluation of historical diurnal temperature range trends in CMIP5 models. Journal of Climate, 26(22), 9077-9089. https://doi.org/10.1175/JCLI-D-13-00032.1.

Lindvall, J., \& Svensson, G. 2015. The diurnal temperature range in the CMIP5 models. Climate Dynamics, 44(1-2), 405-421. https://doi.org/10.1007/s00382-014-2144-2.

Lobell, D. B., \& Asner, G. P. 2003. Climate and management contributions to recent trends in U. S. agricultural yields. Science, 299(5609), 1032-1032. https://doi.org/10.1126/science.1077838

Lobell, D. B., \& Burke, M. B. 2008. Why are agricultural impacts of climate change so uncertain? The importance of temperature relative to precipitation. Environmental Research Letters, 3(3), 034007. http://dx.doi.org/10.1088/1748-9326/3/3/034007.

Lobell, D. B., Schlenker, W., \& Costa-Roberts, J. (2011). Climate trends and global crop production since 1980. Science, 333(6042), 616-620. http://dx.doi.org/10.1126/science.1204531.

Lorenz, R., Pitman, A. J., Donat, M. G., Hirsch, A. L., Kala, J., Kowalczyk, E. A., ... \& Srbinovsky, J. 2014. Representation of climate extreme indices in the ACCESS1. 3b coupled atmosphere-land surface model. Geoscientific Model Development, 7(2), 545-567. https://doi.org/10.5194/gmd-7-545-2014.

Mao, L. 2020. Atlas of Refined Agro-climatic Resources in China. Meteorology(02),288.

Monfreda, C., N. Ramankutty, and J. A. Foley (2008), Farming the planet: 2. Geographic distribution of crop areas, yields, physiological types, and net primary production in the year 2000, Global Biogeochem. Cycles, 22, GB1022, https://doi.org/10.1029/2007GB002947.

Ortiz, R., Sayre, K. D., Govaerts, B., Gupta, R., Subbarao, G. V., Ban, T., \& Reynolds, M. (2008). Climate change: can wheat beat the heat?. Agriculture, Ecosystems \& Environment, 126(1-2), 46-58. https://doi.org/10.1016/j.agee.2008.01.019. 
Rao, A. C. S., Smith, J. L., Jandhyala, V. K., Papendick, R. I., \& Parr, J. F. 1993. Cultivar and climatic effects on the protein content of soft white winter wheat. Agronomy Journal, 85(5), 1023-

1028. https://doi.org/10.2134/agronj1993.00021962008500050013x.

Slafer, G. A., \& Rawson, H. M. (1995). Rates and cardinal temperatures for processes of development in wheat: effects of temperature and thermal amplitude. Functional Plant Biology, 22(6), 913926.https://doi.org/10.1071/PP9950913.

Schlenker, W., \& Roberts, M. J. 2009. Nonlinear temperature effects indicate severe damages to US crop yields under climate change. Proceedings of the National Academy of Sciences, 106(37), 1559415598.https://doi.org/10.1073/pnas.0906865106.

Sillmann, J., Kharin, V. V., Zhang, X., Zwiers, F. W., \& Bronaugh, D. 2013. Climate extremes indices in the CMIP5 multimodel ensemble: Part 1. Model evaluation in the present climate. Journal of Geophysical Research: Atmospheres, 118(4), 1716-1733. https://doi.org/10.1002/jgrd.50203.

Sillmann, J., Kharin, V. V., Zwiers, F. W., Zhang, X., \& Bronaugh, D. 2013. Climate extremes indices in the CMIP5 multimodel ensemble: Part 2. Future climate projections. Journal of Geophysical Research: Atmospheres, 118(6), 2473-2493. https://doi.org/10.1002/jgrd.50188.

Smika, D. E., \& Greb, B. W. 1973. Protein Content of Winter Wheat Grain as Related to Soil and Climatic Factors in the Semiarid Central Great Plains 1. Agronomy Journal, 65(3), 433-

436. https://doi.org/10.2134/agronj1973.00021962006500030023x.

Song, Y. L., \& Dong, W. J. 2006. Influence of drought on winter wheat yield in China during 1961-2000. Journal of Natural Disasters, 15(6), 227-231.

Tao, F., Yokozawa, M., Xu, Y., Hayashi, Y., \& Zhang, Z. 2006. Climate changes and trends in phenology and yields of field crops in China, 1981-2000. Agricultural and forest meteorology, 138(1-4), 82-

92. https://doi.org/10.1016/j.agrformet.2006.03.014

Tao, F., \& Zhang, Z. 2010. Adaptation of maize production to climate change in North China Plain: quantify the relative contributions of adaptation options. European Journal of Agronomy, 33(2), 103116. https://doi.org/10.1016/j.eja.2010.04.002.

Tian, Y., Zheng, C., Chen, J., Chen, C., Deng, A., Song, Z., ... \& Zhang, W. (2014). Climatic warming increases winter wheat yield but reduces grain nitrogen concentration in East China. PloS one, 9(4), e95108. https://doi.org/10.1371/journal.pone.0095108.

Tubiello, F. N., Rosenzweig, C., Goldberg, R. A., Jagtap, S., \& Jones, J. W. (2002). Effects of climate change on US crop production: simulation results using two different GCM scenarios. Part I: wheat, potato, maize, and citrus. Climate Research, 20(3), 259-270. https://doi.org/10.3354/cr020259. 
Vaughan, B., Westfall, D. G., \& Barbarick, K. A. 1990. Nitrogen rate and timing effects on winter wheat grain yield, grain protein, and economics. Journal of Production Agriculture, 3(3), 324-

328. https://doi.org/10.2134/jpa1990.0324.

Viala, E. (2008). Water for food, water for life a comprehensive assessment of water management in agriculture. https://doi.org/10.1007/s10795-008-9044-8.

Wang, B., Feng, P., Li Liu, D., O'Leary, G. J., Macadam, I., Waters, C., ... \& Yu, Q. 2020. Sources of uncertainty for wheat yield projections under future climate are site-specific. Nature Food, 1(11), 720728. https://doi.org/10.1038/s43016-020-00181-w.

Wang, J., Chen, Y., Tett, S. F., Yan, Z., Zhai, P., Feng, J., \& Xia, J. 2020. Anthropogenically-driven increases in the risks of summertime compound hot extremes. Nature communications, 11(1), 1-

11. https://doi.org/10.1038/s41467-019-14233-8.

Wang, K., \& Clow, G. D. 2020. The Diurnal Temperature Range in CMIP6 Models: Climatology, Variability, and Evolution. Journal of Climate, 33(19), 8261-8279. https://doi.org/10.1175/JCLI-D-19-0897.1.

Wang, Y.Yang, H. Y. L. R. Y., \& Hong, C. 1990. Try to discuss the relationships between the seed qualities of wheat and meteorological conditions. Chinese Journal of Agrometeorology, 11(02), 40550.

Wu, J, Gao, X. J. 2013. A gridded daily observation dataset over China region and comparison with the other datasets. Diqiu Wuli Xuebao (in Chinese), 56(4), 1102-1111. https://doi.org/10.6038/cjg20130406.

Wu, Y., Miao, C., Duan, Q., Shen, C., \& Fan, X. 2020. Evaluation and projection of daily maximum and minimum temperatures over China using the high-resolution NEX-GDDP dataset. Climate Dynamics, 55(9), 2615-2629. https://doi.org/10.1007/s00382-020-05404-1.

Xia, J., Yan, Z., Jia, G., Zeng, H., Jones, P. D., Zhou, W., \& Zhang, A. (2015). Projections of the advance in the start of the growing season during the 21 st century based on CMIP5 simulations. Advances in Atmospheric Sciences, 32(6), 831-838. https://doi.org/10.1007/s00376-014-4125-0.

Xu, Y., \& Xu, C.. 2012. Preliminary assessment of simulations of climate changes over China by CMIP5 multi-models. Atmospheric and Oceanic Science Letters, 5(6), 489-

494. https://doi.org/10.1080/16742834.2012.11447041.

You, Q., Wang, D., Jiang, Z., \& Kang, S. 2017. Diurnal temperature range in CMIP5 models and observations on the Tibetan Plateau. Quarterly Journal of the Royal Meteorological Society, 143(705), 1978-1989. https://doi.org/10.1002/qj.3057.

Zhou, B., Wen, Q. H., Xu, Y., Song, L., \& Zhang, X. 2014. Projected changes in temperature and precipitation extremes in China by the CMIP5 multimodel ensembles. Journal of Climate, 27(17), 6591-

6611. https://doi.org/10.1175/JCLI-D-13-00761.1.

Page $17 / 23$ 
Zhou, T., \& Yu, R. 2006. Twentieth-century surface air temperature over China and the globe simulated by coupled climate models. Journal of Climate, 19(22), 5843-5858. https://doi.org/10.1175/JCLI3952.1.

Zhou, Y., \& Ren, G. 2011. Change in extreme temperature event frequency over mainland China, 19612008. Climate Research, 50(2-3), 125-139. https://doi.org/10.3354/cr01053.

\section{Figures}

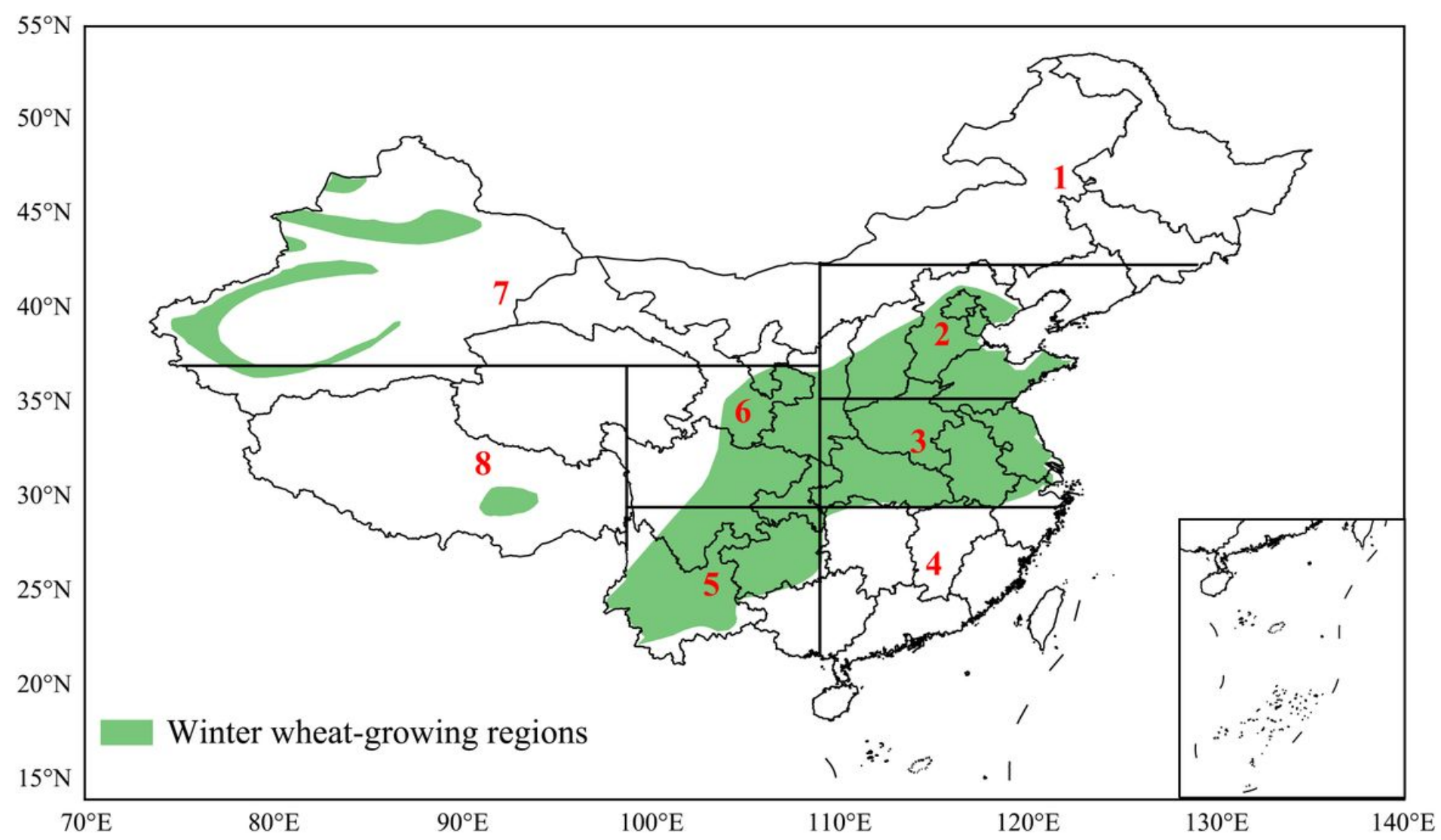

\section{Figure 1}

The regional divisions in China (Subregion 1: Northeast China (NEC), Subregion 2: North China (NC), Subregion 3: Jianghuai (JH), Subregion 4: South China (SC), Subregion 5: Southwest China (SWC), Subregion 6: Chuanyu (CY), Subregion 7: Northwest China (NWC), and Subregion 8: Tibetan Plateau (TP)). 

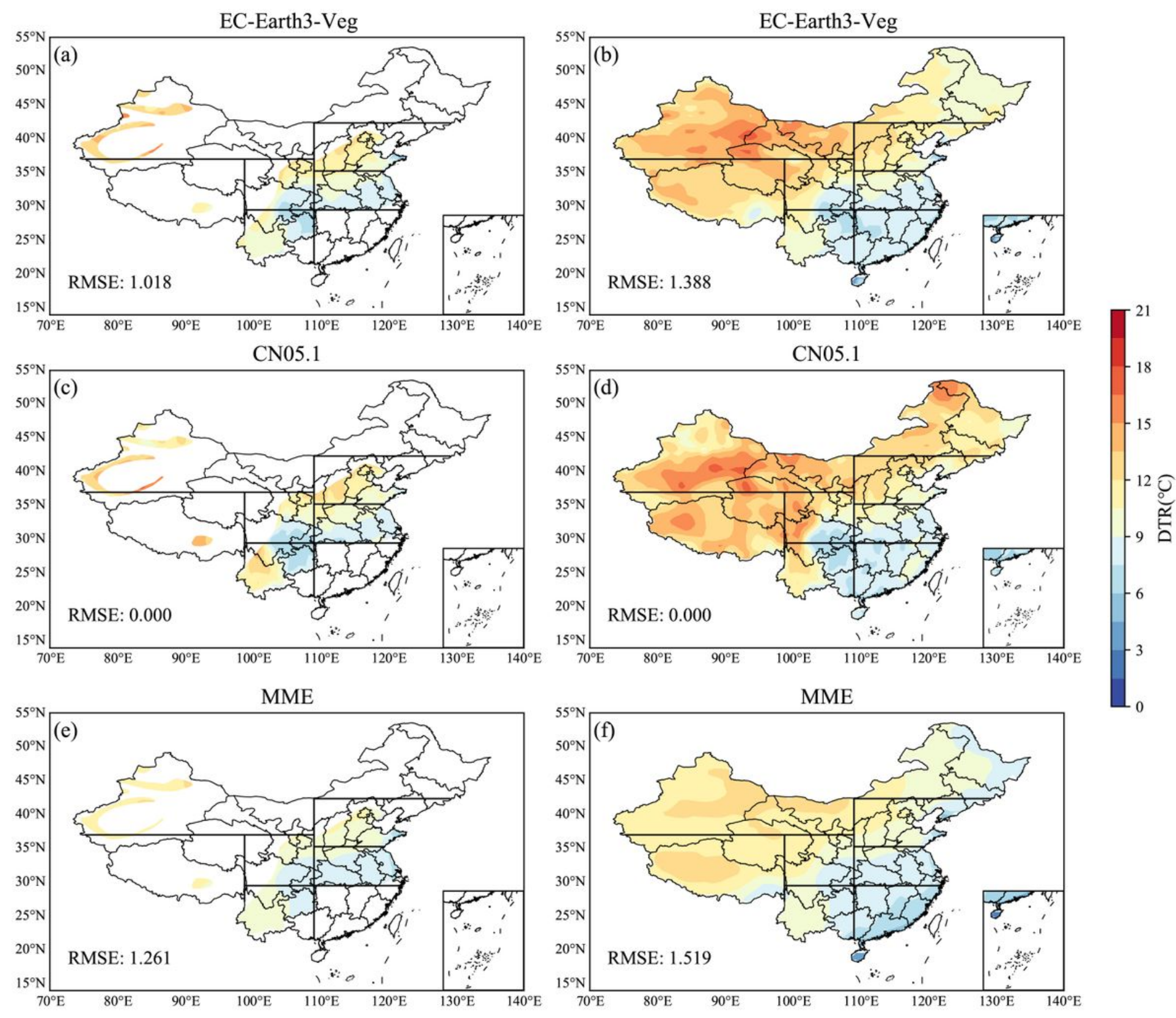

Figure 2

Observation and simulated results of the DTR spatial distribution of climatology during 1995-2014 in China (the left column displays simulated results of DTR in winter wheat-growing regions; the right column shows the national results); (a) and (b) are the models with the highest TS scores. Observation (c) and (d) multimodel ensemble data are shown in (e) (f). 

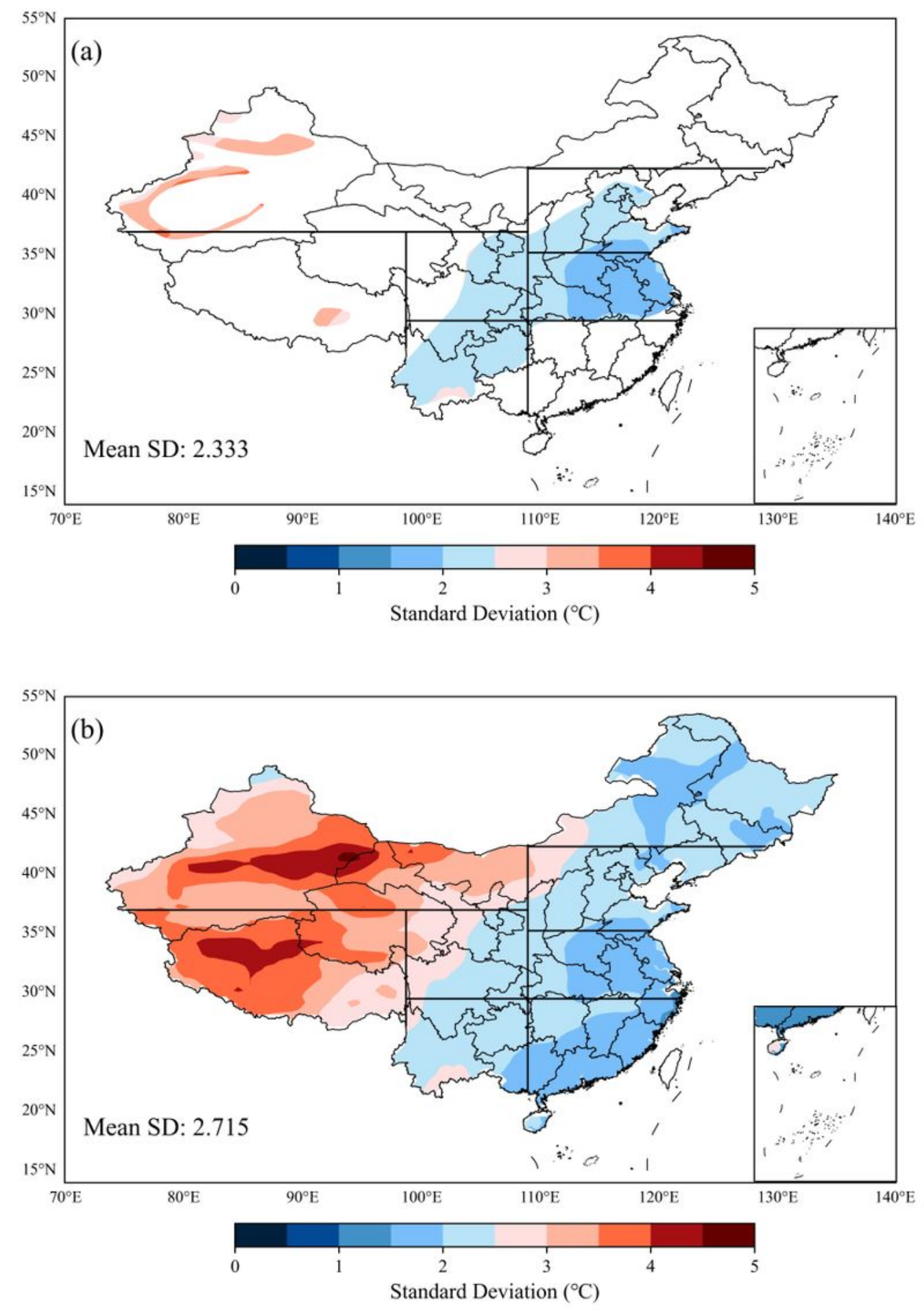

Figure 3

Standard deviations (SD) between CMIP6 models in winter wheat-growing regions (a) and nationwide (b). 


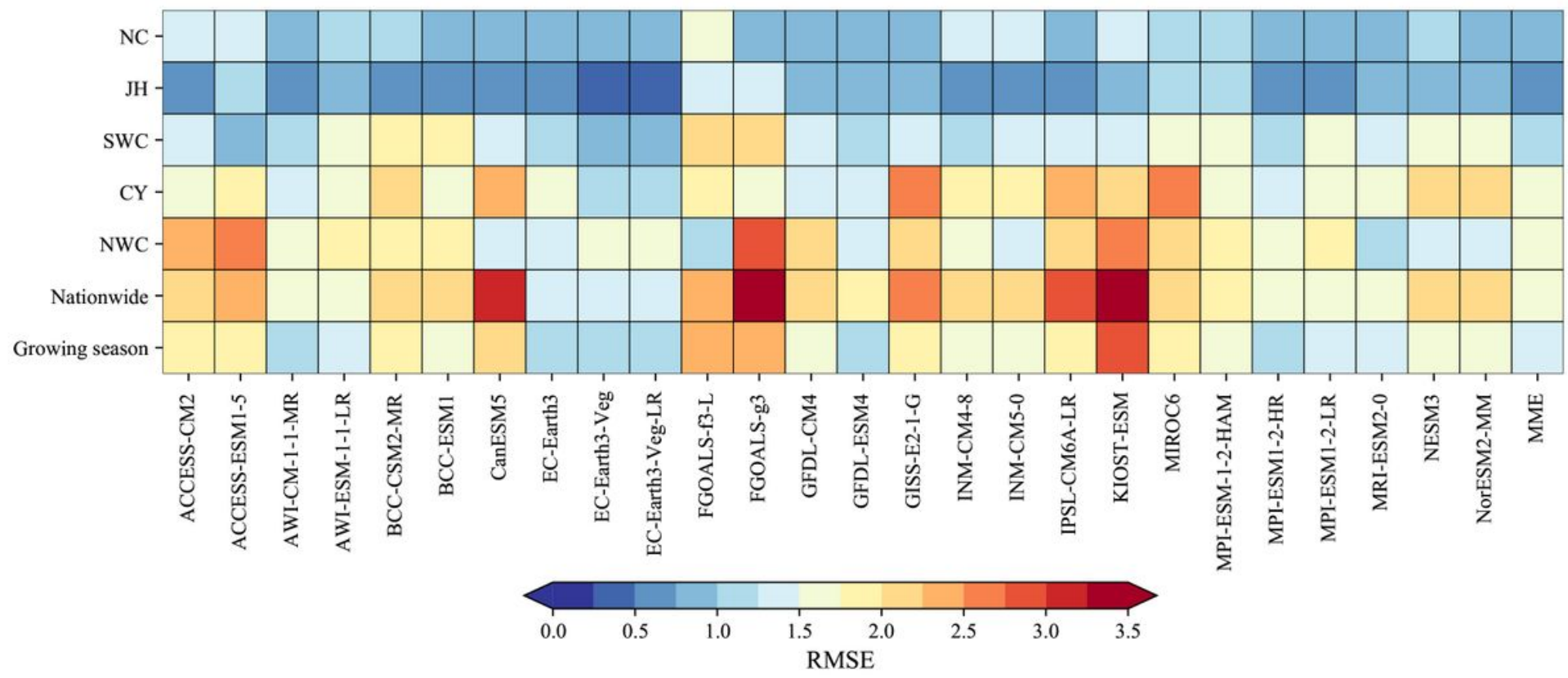

Figure 4

RMSEs of climatological DTR simulated by CMIP6 models in each subregion in China. Each column represents a subregion, and each row represents a CMIP6 model.
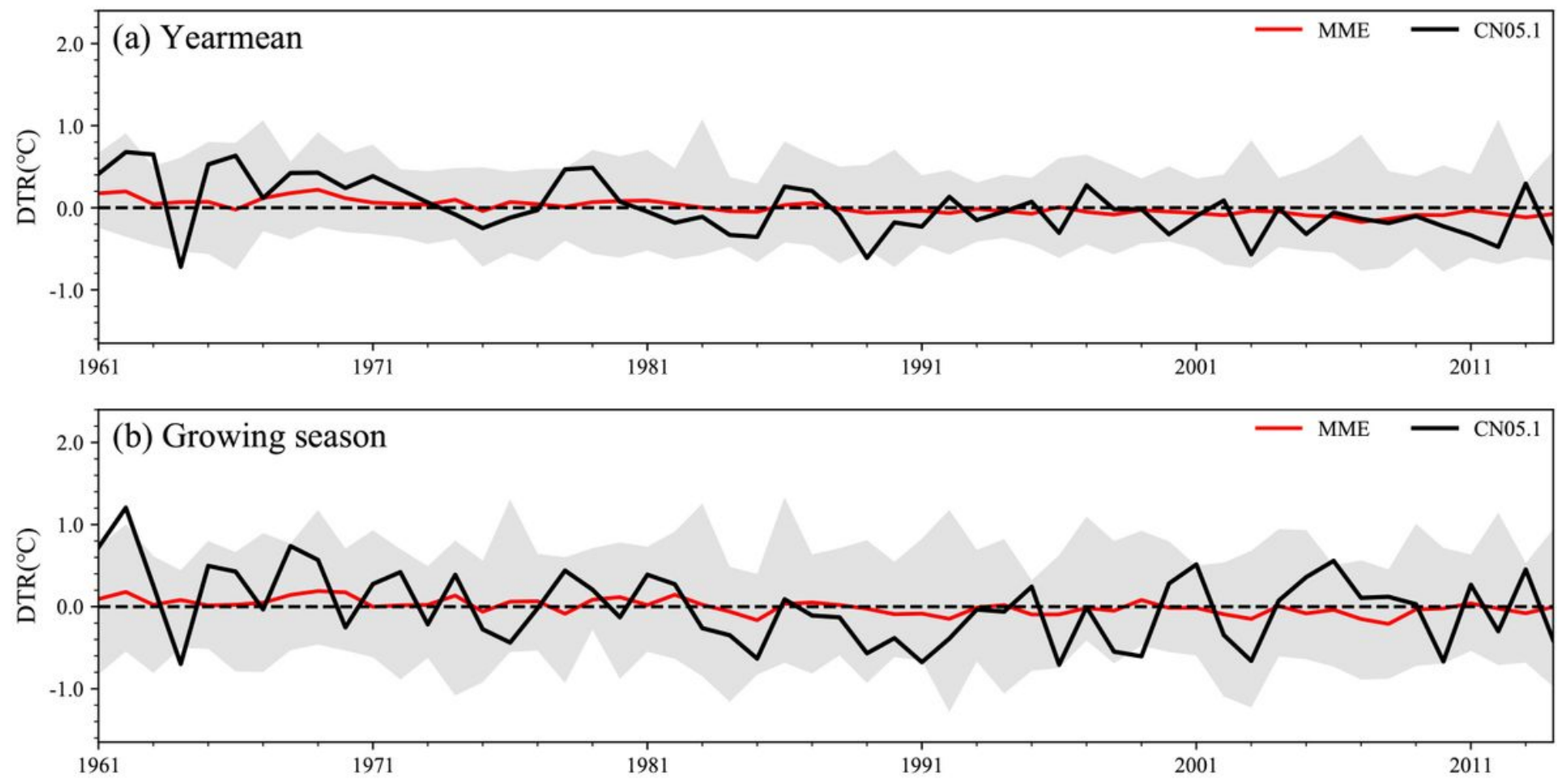

Figure 5

Growing season DTR $\left({ }^{\circ} \mathrm{C}\right)$ time series simulated by CMIP6 models nationwide (a) and in winter wheatgrowing regions (b) in China showing patterns of fluctuations that reflect annually varying correlations of DTR in China. Shading indicates the range of simulations. 


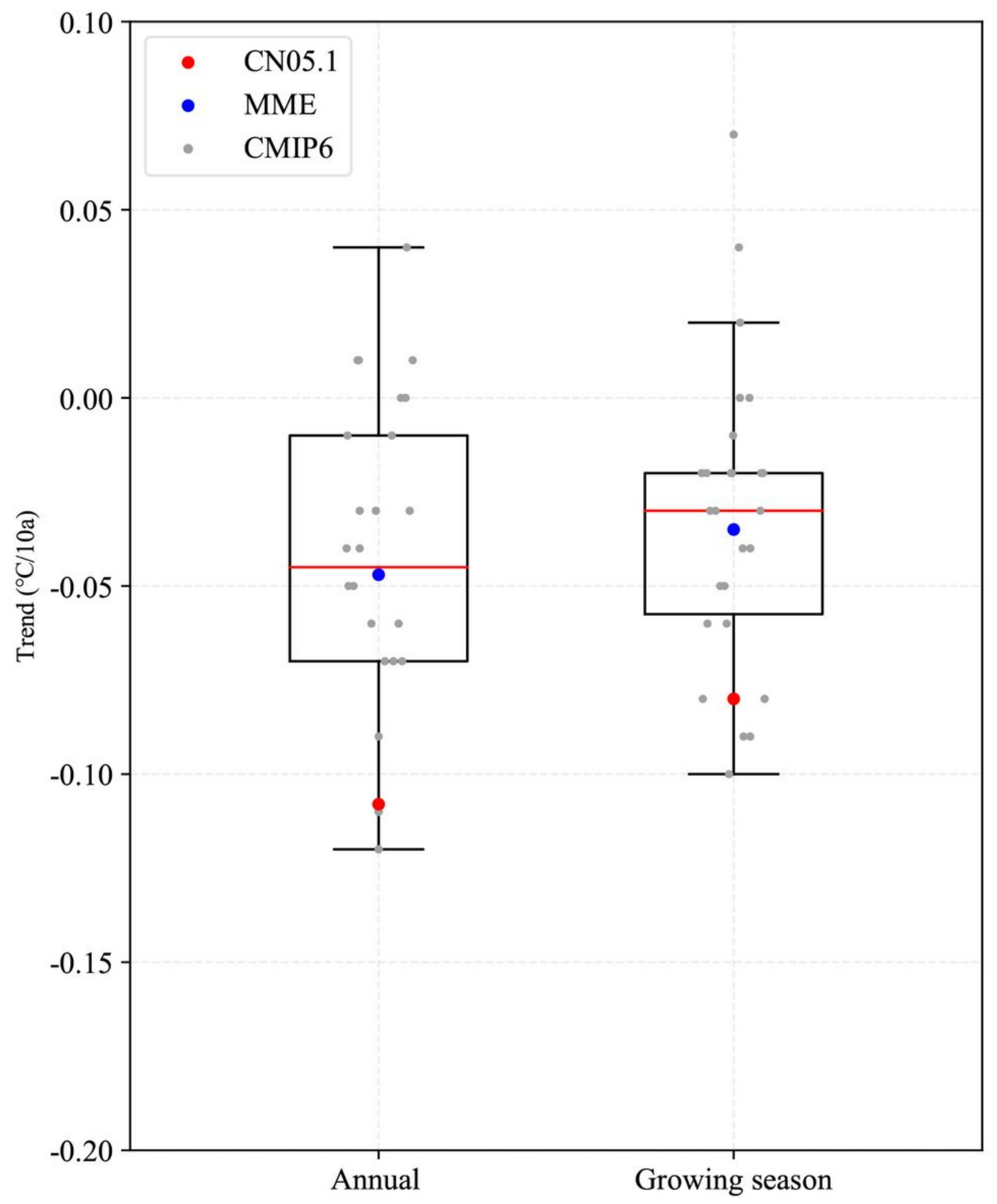

Figure 6

Winter wheat-growing season DTR trends simulated by CMIP6 models and observations. The red lines are the median of model-simulated trends, grey dots are the results of CMIP6 models. These red, blue, and green dots represent the results of CN05.1 and MME, respectively. 


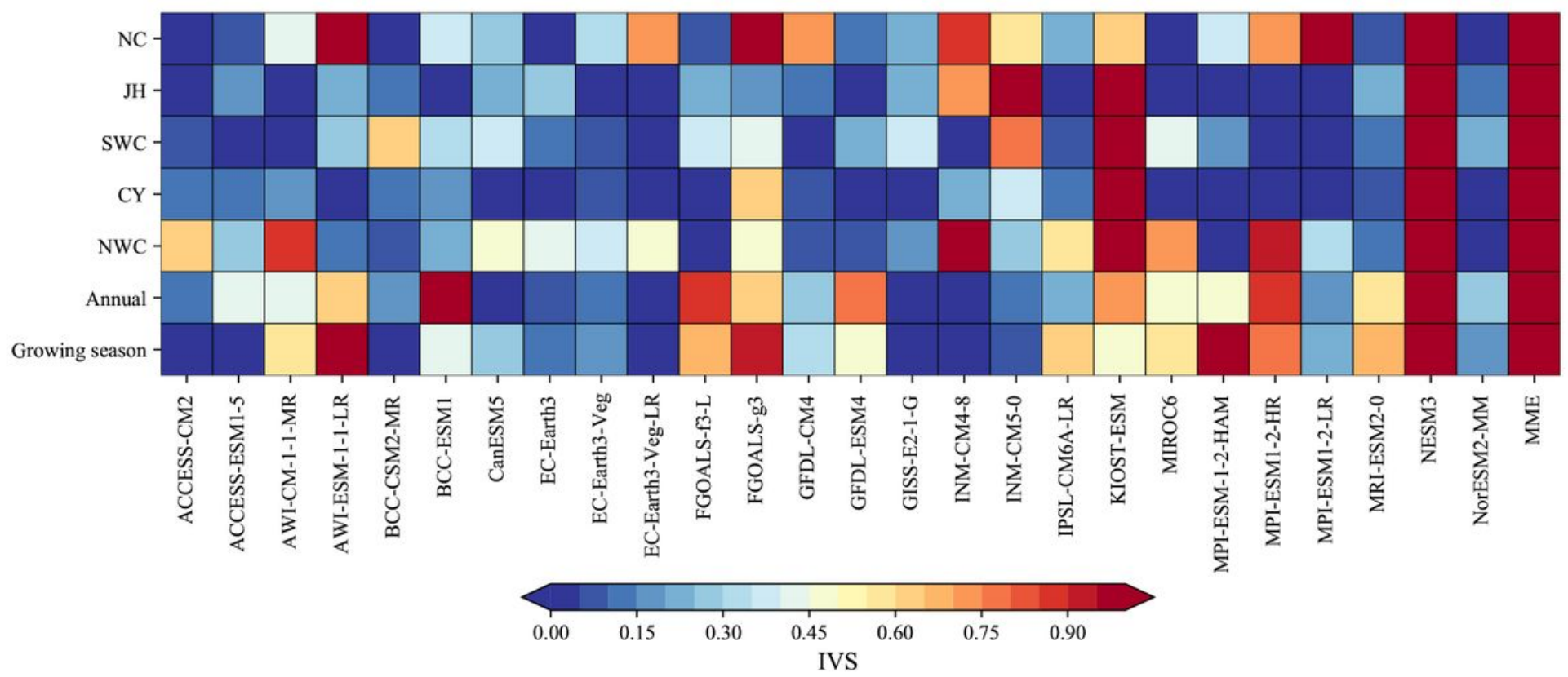

\section{Figure 7}

IVS scores of the annual growing season and annual DTR simulated by CMIP6 models in each subregion in China. Each column represents a subregion, and each row represents a CMIP6 model.

\section{Supplementary Files}

This is a list of supplementary files associated with this preprint. Click to download.

- EditingCertificate.pdf

- declarationStatement.docx 